Article

\title{
Entropy Generation and Natural Convection of CuO-Water Nanofluid in C-Shaped Cavity under Magnetic Field
}

\author{
Ali Chamkha ${ }^{1, *}$, Muneer Ismael ${ }^{2}$, Abbas Kasaeipoor ${ }^{3}$ and Taher Armaghani ${ }^{3}$ \\ 1 Mechanical Engineering Department, Prince Mohammad Bin Fahd University, Al-Khobar 31952, \\ Kingdom of Saudi Arabia \\ 2 Mechanical Engineering Department, College of Engineering, University of Basrah, Basrah 61004, Iraq; \\ muneerismael@yahoo.com \\ 3 Department of Engineering, Mahdishahr Branch, Islamic Azad University, Mahdishahr 75915-35618, Iran; \\ a.kasaeipoor@gmail.com (A.K.); armaghani.taher@yahoo.com (T.A.) \\ * Correspondence: achamkha@pmu.edu.sa; Tel.: +966-13-849-8800; Fax: +966-13-896-4566
}

Academic Editors: Giulio Lorenzini, Omid Mahian and Kevin H. Knuth

Received: 28 November 2015; Accepted: 27 January 2016; Published: 5 February 2016

\begin{abstract}
This paper investigates the entropy generation and natural convection inside a C-shaped cavity filled with $\mathrm{CuO}-$ water nanofluid and subjected to a uniform magnetic field. The Brownian motion effect is considered in predicting the nanofluid properties. The governing equations are solved using the finite volume method with the SIMPLE (Semi-Implicit Method for Pressure Linked Equations) algorithm. The studied parameters are the Rayleigh number $(1000 \leqslant R a \leqslant 15,000)$, Hartman number $(0 \leqslant H a \leqslant 45)$, nanofluid volume fraction $(0 \leqslant \phi \leqslant 0.06)$, and the cavity aspect ratio $(0.1 \leqslant A R \leqslant 0.7)$. The results have shown that the nanoparticles volume fraction enhances the natural convection but undesirably increases the entropy generation rate. It is also found that the applied magnetic field can suppress both the natural convection and the entropy generation rate, where for $R a=1000$ and $\phi=0.04$, the percentage reductions in total entropy generation decreases from $96.27 \%$ to $48.17 \%$ for $H a=45$ compared to zero magnetic field when the aspect ratio is increased from 0.1 to 0.7. The results of performance criterion have shown that the nanoparticles addition can be useful if a compromised magnetic field value represented by a Hartman number of 30 is applied.
\end{abstract}

Keywords: entropy generation; natural convection; C-shaped cavity; nanofluid; magnetic field

\section{Introduction}

Nowadays, energy saving and environmental agencies strictly recommend energy conservation in order to save what remains of energy sources of the world and to reduce pollution. Hence, optimization of thermal systems has received unique attention. Recently, second-law-based investigations have gained attention for studying thermal systems. Entropy generation has been used as a gauge to evaluate the performance of a thermal system. Bejan [1-3] focused on the different reasons behind entropy generation in applied thermal engineering. Generation of entropy destroys available work of a system. Therefore it makes good engineering sense to focus on irreversibility of heat transfer and fluid friction process. Second-law analysis in ordinary fluids filling clear cavities can be summarized as follow. Mahmoud and Fraser [4] applied the first and second laws of thermodynamics to forced convection inside a cylindrical annular space with isoflux boundary conditions. Mahmud and Sadrul Islam [5] applied the second law of thermodynamics to predict the nature of irreversibility in inclined wavy wall cavity. Bouabid et al. [6] studied the transient state study of entropy generation in inclined cavity with various aspect ratios. Cheng and Liang [7] concluded that the applicability of the entropy 
generation minimization to optimize thermodynamic systems is conditional if the maximum output power is the objective.

Analyses of the second law of thermodynamics are also focused on saturated porous cavities, as in Baytas [8], Al-Hadhrami et al. [9], Mahmud and Fraser [10], Hooman and Ejlali [11], Zahmatkesh [12], Varol et al. [13], and Basak et al. [14].

The low thermal conductivity of conventional heat transfer fluids, common water, oil, and ethylene glycol, has restricted the improvement of thermal systems performance. Fluids containing nano-sized solid particles offer a possible solution to conquer this problem. The nanofluid has greater effective thermal conductivity than a pure base fluid. Nanofluids, a name conceived by Choi [15], are fluids consisting of solid nanoparticles with size less than $100 \mathrm{~nm}$ suspended with a specified solid volume fraction. Nanofluids can be used to improve thermal management systems in many engineering applications such as transportation, micromechanics instrument and cooling devices. Due to the encouraged enhanced properties associated with nanofluids properties, huge works have been published since about two decades ago (Aminossadati and Ghasemi [16], Ghasemi and Aminossadati [17], Abu-Nada and Chamkha [18], Nemati et al. [19], Mahmoudi et al. [20], Matin and Pop [21], Sheikhzadeh et al. [22], and Sheikholeslami et al. [23,24]).

Recently, the analysis of the second law of thermodynamics is directed at the handling of nanofluids, as in Kashani et al. [25] who investigated the entropy generation due to laminar natural convection of $\mathrm{Cu}$-water nanofluid near the density maximum of water in a two-dimensional enclosure with various patterns of vertical wavy walls. Cho et al. [26] studied the heat transfer performance and entropy generation of natural convection in a nanofluid-filled U-shaped cavity. Ting et al. [27] studied the entropy generation of viscous dissipative nanofluid flow in thermal non-equilibrium porous media embedded in micro channels. Mahmoudi at al. [28] examined the natural convection in a square enclosure filled with a water- $\mathrm{Al}_{2} \mathrm{O}_{3}$ nanofluid in the presence of magnetic field and uniform heat generation/absorption. Aghaei et al. [29] evaluated the effects of magnetic field on heat transfer and entropy generation on mixed convection of nanofluids with variable properties in a trapezoidal enclosure. Kefayati [30] analyzed the heat transfer and entropy generation on laminar natural convection of non-Newtonian nanofluids in the presence of an external horizontal magnetic field in a square cavity. Ellahi et al. [31] analyzed a mathematical model in order to study the shape of nanosize particles on entropy generation and natural convection boundary layer flow along an inverted cone. More recently, Ismael et al. [32] studied the entropy generation due to conjugate natural convection conduction heat transfer in a square domain under steady-state condition. They proposed a new criterion for assessment of the thermal performance. As the applications of natural convection in engineering systems have developed, it became necessary to investigate non rectangular/square cavity shape. Cooling of electronic chips/system, micro-electro-mechanical systems (MEMS), solar collectors, and heat exchangers are some of the many important applications that handle different cavity shapes. Biserani et al. [33] used Bejan's constructal theory to optimize the geometry of $\mathrm{H}$-shaped cavity that intrudes into a solid conducted wall. They optimized other cavities namely, C-shaped and T-shaped cavities and found that $\mathrm{H}$-shaped is superior in thermal performance. Mahmoodi [34] studied free convection in L-shaped cavity filled with Cu-water nanofluid. Mahmood and Hashemi [35] studied the C-shaped cavity filled with a nanofluid. Cho et al. [36] investigated the natural convection enhancement of $\mathrm{Al}_{2} \mathrm{O}_{3}$-water nanofluid in a U-shaped cavity. Mansour et al. [37] also investigated the natural convection inside $\mathrm{U}$-shaped cavity filled with $\mathrm{Cu}$-water nanofluid but they termed their cavity as C-shaped. Mojumder et al. [38] studied the natural convection in C-shaped cavity filled with Cobalt-kerosene ferrofluid under the effect of externally applied magnetic field. Kasaeipoor et al. [39] studied the convection of $\mathrm{Cu}$-Water nanofluid in a vented T-shaped cavity in the presence of an externally applied magnetic field. Al-Zamily [40] investigated numerically the effect of constant magnetic field on natural convection in a semi-circular enclosure filled with $\mathrm{Cu}$-water nanofluid with the present of heat flux.

The literature survey above led us to be sure that the entropy generation in C-shaped cavity filled with a nanofluid and subjected to a magnetic field has not been investigated yet. Therefore, this topic 
will be the material of the present paper. It is believed that this study will contribute to improving the thermal performance of electronic chip cooling systems.

\section{Problem Description and Mathematical Modeling}

The geometry of the present study is a C-shaped cavity filled with a CuO-water nanofluid and subjected to a horizontal uniform magnetic field $\left(B_{0}\right)$, which is shown in Figure 1. The two-dimensional cavity has equal length and height of $L$. The internal walls of cavity with the length $H$ are maintained at a relatively low temperature $T_{c}$. The external right walls are insulated and the other walls are maintained at a relatively high temperature $T_{h}$. The flow is assumed to be laminar, steady, and incompressible. The nanofluid is assumed to be Newtonian, incompressible and has a low electrical conductivity. Moreover, the water and $\mathrm{CuO}$ nanoparticles are in thermal equilibrium. The Joule heating are assumed to be negligible compared to the applied magnetic field.

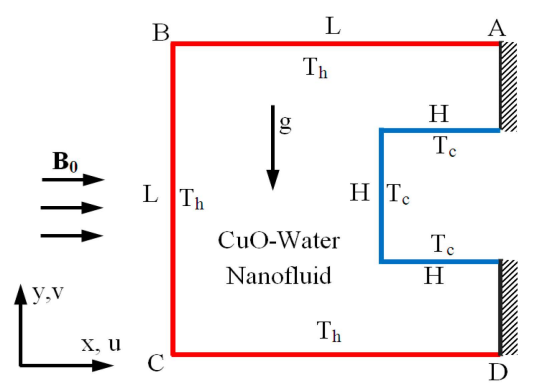

Figure 1. Schematic of C-shaped cavity under magnetic field.

The equations that govern the conservation of mass, momentum and energy can be written as

$$
\begin{gathered}
\frac{\partial u}{\partial x}+\frac{\partial v}{\partial y}=0 \\
u \frac{\partial u}{\partial x}+v \frac{\partial u}{\partial y}=\frac{1}{\rho_{n f}}\left[-\frac{\partial p}{\partial x}+\mu_{n f}\left(\frac{\partial^{2} u}{\partial x^{2}}+\frac{\partial^{2} u}{\partial y^{2}}\right)\right] \\
u \frac{\partial v}{\partial x}+v \frac{\partial v}{\partial y}=\frac{1}{\rho_{n f}}\left[-\frac{\partial p}{\partial y}+\mu_{n f}\left(\frac{\partial^{2} v}{\partial x^{2}}+\frac{\partial^{2} v}{\partial y^{2}}\right)\right]+(\rho \beta)_{n f} g\left(T-T_{c}\right)-\sigma_{n f} B_{0}^{2} v \\
u \frac{\partial T}{\partial x}+v \frac{\partial T}{\partial y}=\alpha_{n f}\left[\frac{\partial^{2} T}{\partial x}+\frac{\partial^{2} T}{\partial y^{2}}\right]
\end{gathered}
$$

where $u, v$ and $T$ are the velocity components in the $x$ direction, $y$ direction and temperature, respectively. The local entropy generation equation given in [1] can be adopted for nanofluid as:

$$
S_{c}=\frac{k_{n f}}{T_{0}^{2}}\left[\left(\frac{\partial T}{\partial x}\right)^{2}+\left(\frac{\partial T}{\partial y}\right)^{2}\right]+\frac{\mu_{n f}}{T_{0}}\left[2\left\{\left(\frac{\partial u}{\partial x}\right)^{2}+\left(\frac{\partial v}{\partial y}\right)^{2}\right\}+\left(\frac{\partial u}{\partial y}+\frac{\partial v}{\partial x}\right)^{2}\right]
$$

The dimensionless form of the governing equations can be obtained by introducing the dimensionless variables. These are given as follows:

$$
\begin{gathered}
X=\frac{x}{L}, Y=\frac{y}{L}, U=\frac{u L}{\alpha_{f}}, V=\frac{v L}{\alpha_{f}}, A R=\frac{H}{L}, P=\frac{p L^{2}}{\rho_{n f} \alpha_{f}{ }^{2}}, \theta=\frac{T-T_{c}}{T_{h}-T_{c}} \\
R a=\frac{g \beta_{f} L^{3}\left(T_{h}-T_{c}\right)}{\alpha_{f} v_{f}}, H a=B_{0} L \sqrt{\frac{\sigma_{f}}{\mu_{f}}}, \operatorname{Pr}=\frac{v_{f}}{\alpha_{f}}
\end{gathered}
$$

Based on these dimensionless variables, the continuity, momentum and energy equations for the laminar and steady-state mixed convection of nanofluid in the presence of magnetic field can be written in non-dimensional form: 


$$
\begin{gathered}
\frac{\partial U}{\partial X}+\frac{\partial V}{\partial Y}=0 \\
U \frac{\partial U}{\partial X}+V \frac{\partial U}{\partial Y}=-\frac{\partial P}{\partial X}+\frac{\mu_{n f}}{\rho_{n f} \alpha_{f}}\left[\frac{\partial^{2} U}{\partial X^{2}}+\frac{\partial^{2} U}{\partial Y^{2}}\right] \\
U \frac{\partial V}{\partial X}+V \frac{\partial V}{\partial Y}=-\frac{\partial P}{\partial Y}+\frac{\mu_{n f}}{\rho_{n f} \alpha_{f}}\left[\frac{\partial^{2} V}{\partial X^{2}}+\frac{\partial^{2} V}{\partial Y^{2}}\right]-\frac{\rho_{f} \sigma_{n f}}{\rho_{n f} \sigma_{f}} H a^{2} \operatorname{Pr} V+\frac{(\rho \beta)_{n f}}{\rho_{n f} \beta_{f}} R a \operatorname{Pr} \theta \\
U \frac{\partial \theta}{\partial X}+V \frac{\partial \theta}{\partial Y}=\frac{\alpha_{n f}}{\alpha_{f}}\left[\frac{\partial^{2} \theta}{\partial X^{2}}+\frac{\partial^{2} \theta}{\partial Y^{2}}\right]
\end{gathered}
$$

In dimensionless forms, local entropy generation can be expressed as following:

$$
\begin{gathered}
S_{c}^{*}=\left[\left(\frac{\partial \theta}{\partial X}\right)^{2}+\left(\frac{\partial \theta}{\partial Y}\right)^{2}\right]+\frac{\mu_{n f} k_{f}}{\mu_{f} k_{n f}} \frac{B r}{\Omega U^{2}}\left[2 \times\left\{\left(\frac{\partial U}{\partial X}\right)^{2}+\left(\frac{\partial V}{\partial Y}\right)^{2}\right\}+\left(\frac{\partial U}{\partial Y}+\frac{\partial V}{\partial X}\right)^{2}\right] \\
S_{c}^{*}=\frac{S_{c}}{S_{G, c}}, \text { and } S_{G, c}=\frac{k(\Delta T)^{2}}{L^{2} T_{0}^{2}}, B r=\frac{\mu u^{2}}{k \Delta T}=E c \operatorname{Pr}, \Omega=\frac{\Delta T}{T_{0}}
\end{gathered}
$$

where $\Omega, S_{c}^{*}$, and $B r$ are dimensionless temperature difference ratio, dimensionless local entropy generation and Brinkman number, respectively. Brinkman number determines the relative importance between dissipation effects and fluid conduction effects [4]. In the present study, the ratio $\mathrm{Br} / \Omega$ is fixed at 1.0.

As the distribution of volumetric entropy generation is obtained, it would be integrated over the whole domain to yield the global entropy generation (GEG) rate:

$$
S_{m}=\iint_{\forall} S_{c}^{*} d \forall
$$

The non-dimensional boundary conditions along the cavity walls are described as follows: $U$, $V=0$ on all the walls; $\theta=1$ on the heat source; $\theta=0$ on the cool walls; and $\partial \theta / \partial X=0$ for adiabatic walls.

The thermo-physical properties of pure water (base fluid) and the $\mathrm{CuO}$ nanoparticles, at a constant temperature of $25^{\circ} \mathrm{C}$, are listed in Table $1[41,42]$.

Table 1. Thermo physical properties of water and $\mathrm{CuO}$ nanoparticles [41,42].

\begin{tabular}{ccc}
\hline Physical properties & Fluid phase & $\mathrm{CuO}$ \\
\hline$C_{p}(\mathrm{j} / \mathrm{kg} \cdot \mathrm{K})$ & 4179 & 540 \\
$\rho(\mathrm{kg} / \mathrm{m} 3)$ & 997.1 & 6500 \\
$\mathrm{Pr}$ & 6.2 & - \\
$k(\mathrm{w} / \mathrm{m} \cdot \mathrm{K})$ & 0.613 & 18 \\
$\beta\left(\mathrm{k}^{-1}\right)$ & $21 \times 10^{-5}$ & $5.1 \times 10^{-5}$ \\
$\sigma(\mu \mathrm{S} / \mathrm{cm})$ & 0.05 & $2.7 \times 10^{-8}$ \\
\hline
\end{tabular}

The effective density of the nanofluid is defined as follows:

$$
\rho_{n f}=(1-\phi) \rho_{f}+\phi \rho_{s}
$$

where $\phi$ is the solid volume fraction. The thermal diffusivity of the nanofluid is defined as follows:

$$
\alpha_{n f}=\frac{k_{n f}}{\left(\rho c_{p}\right)_{n f}}
$$

The heat capacitance and the thermal expansion coefficient of the nanofluid are given as follows [18]: 


$$
\left(\rho c_{p}\right)_{n f}=(1-\phi)\left(\rho c_{p}\right)_{f}+\phi\left(\rho c_{p}\right)_{s},(\rho \beta)_{n f}=(1-\phi)(\rho \beta)_{f}+\phi(\rho \beta)_{s}
$$

The diameter of nanoparticles $\left(d_{s}\right)$ is $33 \mathrm{~nm}$. The effective viscosity of CuO-water nanofluid, its Brownian-motion velocity and the effect of water temperature on this motion, can be expressed as follows [43]:

$$
\frac{\mu_{\mathrm{nf}}}{\mu_{\mathrm{f}}}=1+\frac{\rho_{s} V_{b r} d_{s}^{2}}{72 \mathrm{~N} \delta}, V_{b r}=\frac{1}{d_{s}}\left(\frac{18 k_{b} T}{\pi \rho_{s} d_{s}}\right)^{1 / 2}
$$

where $\rho_{s}$ is the nanoparticles density. In addition, $\delta$ denotes the nanoparticles average central distance and $N$ is a parameter for empirical data fitting. They are written as follows:

$$
\delta=\left(\frac{\pi}{6 \phi}\right)^{1 / 3} \times d_{s}, N=\left(\mathrm{c}_{1} \phi+\mathrm{c}_{2}\right) d_{s}+\left(\mathrm{c}_{3} \phi+\mathrm{c}_{4}\right)
$$

where $c_{1}=-1.133 \times 10^{-6}, c_{2}=-2.771 \times 10^{-6}, c_{3}=9 \times 10^{-8}$ and $c_{4}=-3.93 \times 10^{-7}$.

Chon et al. [44] proposed the following empirical relation for the thermal conductivity of $\mathrm{Al}_{2} \mathrm{O}_{3}$-water nanofluid with spherical particles:

$$
\frac{k_{\mathrm{nf}}}{k_{\mathrm{f}}}=1+64.7 \phi^{0.74}\left(\frac{d_{\mathrm{f}}}{d_{\mathrm{s}}}\right)^{0.369} \times\left(\frac{k_{\mathrm{s}}}{k_{\mathrm{f}}}\right)^{0.747} \operatorname{Pr}^{0.9955} \operatorname{Re}_{\mathrm{s}}^{1.2321}
$$

In Equation (13),

$$
\operatorname{Re}_{\mathrm{s}}=\frac{\rho_{\mathrm{f}} k_{b} T}{3 \pi\left[A_{1} \times 10^{A_{2} /\left(T-A_{3}\right)}\right]^{2} l_{f}}, A_{1}=2.414 \times 10^{-5}, A_{2}=247.8, A_{3}=140
$$

$\mathrm{Re}_{\mathrm{s}}$ is defined as the nanoparticles Reynolds number. In addition, $l_{\mathrm{f}}=17 \mathrm{~nm}$ is mean free path of water. The accuracy of the above-mentioned equation was also confirmed by Mintsa et al. [45] for CuO and adopted afterwards in many studies, such as by Popa et al. [46].

The effective electrical conductivity of nanofluid was presented by Maxwell [47] as follows:

$$
\frac{\sigma_{n f}}{\sigma_{f}}=1+\frac{3(\gamma-1) \phi}{(\gamma+2)-(\gamma-1) \phi}, \gamma=\frac{\sigma_{s}}{\sigma_{f}}
$$

The local Nusselt number over the heat transfer walls is calculated by:

$$
N u=-\frac{k_{n f}}{k_{f}}\left(\frac{\partial \theta}{\partial n}\right)_{n} \text { with } n=(X, Y)
$$

The mean Nusselt number over the heat transfer walls is evaluated as:

$$
N u_{m}=\frac{1}{3}\left[\int_{A}^{B} N u d X+\int_{B}^{C} N u d Y+\int_{C}^{D} N u d X\right]
$$

\section{Numerical Solution and Grid Dependency Test}

Finite volume method using a collocated grid system have been used to solve the governing Equation (4). The computational domain has been uniformly discretized using displaced network method. Central difference scheme was used to discretize diffusion terms, whereas the upwind scheme was adopted for convection terms. The SIMPLE (Semi-Implicit Method for Pressure Linked Equations) algorithm [48] was followed for pressure velocity linkage. All numerical efforts were achieved by an in house-built FORTRAN computer code (FORTRAN 90). Given that the basis of the solving algorithm lays on an iterative technique, the following convergence criterion is used: 


$$
\sum_{\mathrm{j}} \sum_{i} \sqrt{\left[\left.\frac{\delta^{n+1}-\delta^{n}}{\delta^{n+1}}\right|_{i, j}\right]^{2}} \leqslant 10^{-8}
$$

where $\delta$ may be any variable of $(U, V, \theta)$. Once the variables $U, V$, and $\theta$ are obtained, the local entropy generation is calculated using Equation (5).

It is necessary to examine the dependency of the simulation results to the grid structure. For this purpose, the effect of the grid points number on the average Nusselt number has been evaluated. The results for $H a=30, \phi=0.04, A R=0.1,0.7$ and $R a=1000,15,000$ are listed in Table 2. As shown, it is clear that for any grid structure that is finer than $100 \times 100$, the average Nusselt number remains unchanged. Thus, a uniform grid with the size of $100 \times 100$ for this study has been selected (Figure 2). In order to verify the written code with others, a comparison has been made with selected results reported in [35]. The average Nusselt number was investigated in a C-shaped cavity with three internal cold walls and three external hot walls, the results of which are shown in Figure 3. As shown, difference between the present study and results reported in [35] is acceptable. Extra comparison with Pirmohammadi and Ghasemi [49] was achieved at zero inclination angle and $\mathrm{Ra}=10^{5}$ for different Hartman number. The comparison results are tabulated in Table 3, and they further guarantee the validity of the present numerical code.

Table 2. Grid independency study $(\phi=0.04$ and $H a=30)$.

\begin{tabular}{ccccccc}
\hline Grid points & & $\mathbf{4 0} \times \mathbf{4 0}$ & $\mathbf{6 0} \times \mathbf{6 0}$ & $\mathbf{8 0} \times \mathbf{8 0}$ & $\mathbf{1 0 0} \times \mathbf{1 0 0}$ & $\mathbf{1 2 0} \times \mathbf{1 2 0}$ \\
\hline \multirow{2}{*}{$\mathrm{AR}=0.1$} & $R a=1000$ & 0.6884 & 0.6771 & 0.6333 & 0.6328 & 0.6328 \\
& $R a=15,000$ & 0.6851 & 0.6674 & 0.6617 & 0.6605 & 0.6604 \\
$\mathrm{AR}=0.7$ & $R a=1000$ & 5.2215 & 5.2069 & 5.2018 & 5.2008 & 5.2007 \\
& $R a=15,000$ & 5.2433 & 5.2163 & 5.2052 & 5.2026 & 5.2024 \\
\hline
\end{tabular}

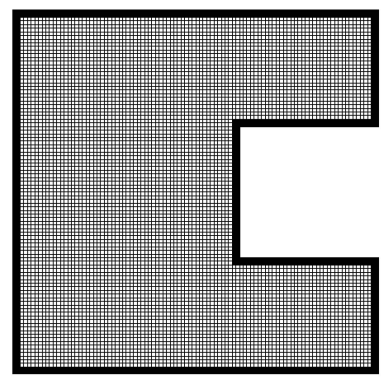

Figure 2. Schematic presentation of the grid.

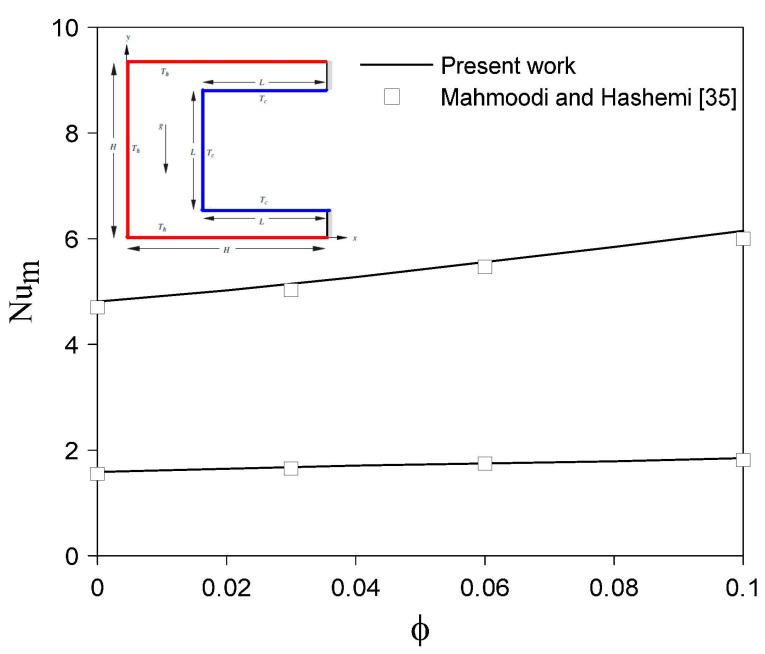

Figure 3. Validation of the present code against Mahmoodi and Hashemi [35] for a Cu-water nanofluid natural convection in cavity. 
Table 3. Comparison of mean Nusselt number with [49] for $R a=10^{5}$.

\begin{tabular}{cccc}
\hline Hartman Number & Present & Pirmoammadi and Ghasemi [49] & Percentage error \\
\hline 50 & 1.0104 & 1.0188 & $-0.82 \%$ \\
70 & 1.8121 & 1.8372 & $-1.36 \%$ \\
\hline
\end{tabular}

\section{Results and Discussion}

The results are gathered by inspecting the effects of Rayliegh number $1000 \leqslant R a \leqslant 15,000$, Hartman number $0 \leqslant H a \leqslant 45$, nanoparticles volume fraction $0 \leqslant \phi \leqslant 0.06$ and cavity aspect ratio $0.1 \leqslant A R \leqslant 0.7$ on the flow, thermal, and entropy generation fields and are presented in the following subsections. The effect of nanoparticles volume fraction is included in each subsection.

\subsection{Effect of Raylirgh Number}

Contour maps of streamlines, isotherms, and isentropic lines for different $R a$ values at $H a=30$, $\phi=0.04$, and $A R=0.3$ are presented in Figure 4 . The streamlines manifests a single vortex behavior. Due to the imposed thermal boundary conditions, the vortex rotates clockwise with its core localized within the main cavity. Increasing $R a$ from 1000 to 15,000 leads to strengthening the vortex rotation. The nanofluid fluid is intensified close to the vertical cold wall of the rib where relatively denes streamlines are noticed. Undisturbed isotherms with C-shaped behavior is noticed up to $R a=10,000$. Beyond this value, a small perturbation takes place on the isotherms and crowded isotherms close to the rib upper edge are seen. However, evenly disturbed isotherms within the lower and upper grooves are still present with all $R a$ values. The isentropic contours show that the entropy generation is concentrated along the cold vertical wall of the rib and along a substantial part of the hot vertical wall. The remainder of the cavity behaves as an "idle" region from the entropy generation point of view. The streamlines and the isotherms above lead to attribute the entropy concentrators mainly to the nanofluid friction irreversibility.

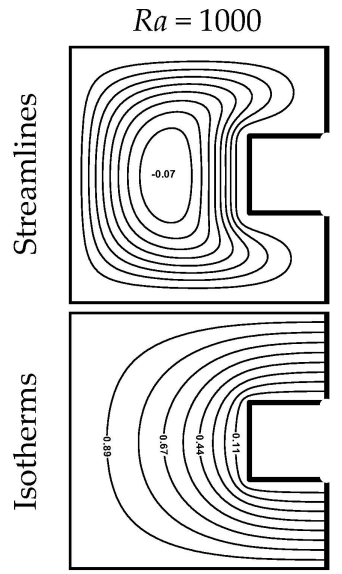

$R a=1000$

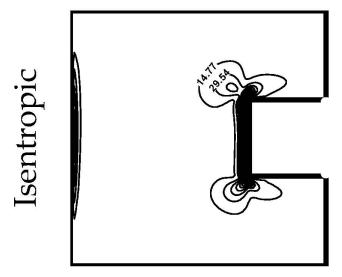

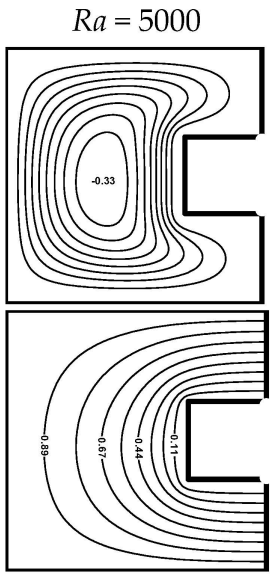

$R a=5000$

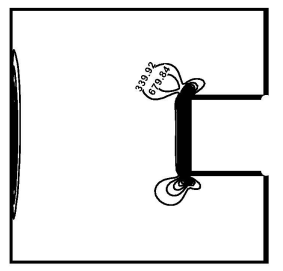

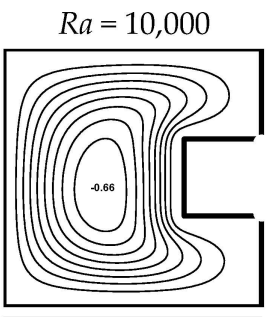

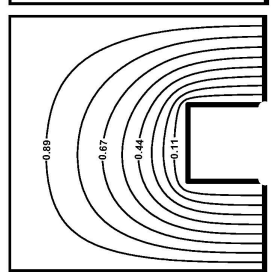

$R a=10,000$

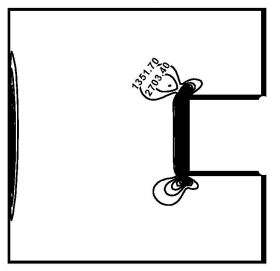

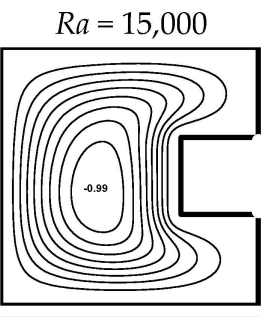

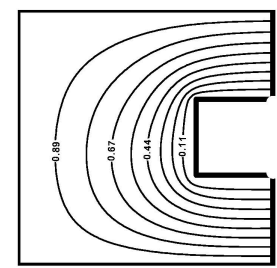

$R a=15,000$

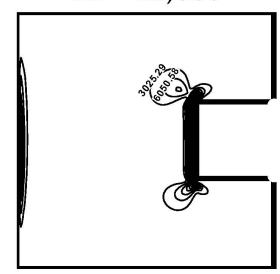

Figure 4. The effects of Rayleigh on the Streamlines, Isotherms and Isentropic lines for nanofluid $\phi=0.04)$ at $H a=30$ and $A R=0.3$. 
The parameters of Figure 4 above are adopted in depicting the distribution of local Nusselt number $N u$ along the hot walls. The results are presented in Figure 5, which shows that most of the convective heat transfer takes place along the horizontals hot walls. The local Nusselt number along the upper hot wall is an increasing function of $R a$ number, while it is a decreasing function of $R a$ along the lower hot wall. Relatively little variation of $N u$ takes place along the vertical hot wall (BC). Globally, the overall heat transfer is, as expected, an increasing function of $R a$ due to the dominance of inertia force over the viscous one. This can be drawn from the variation of the average Nusselt number over the hot walls, which is presented in Figure 6. However, a linear increase of the $N u_{m}$ with the nanoparticles volume fraction $\phi$ is recorded with all studied $R a$ values. This can be surely attributed to the enhanced thermal energy transport due to the enhanced nanofluid thermal conductivity.

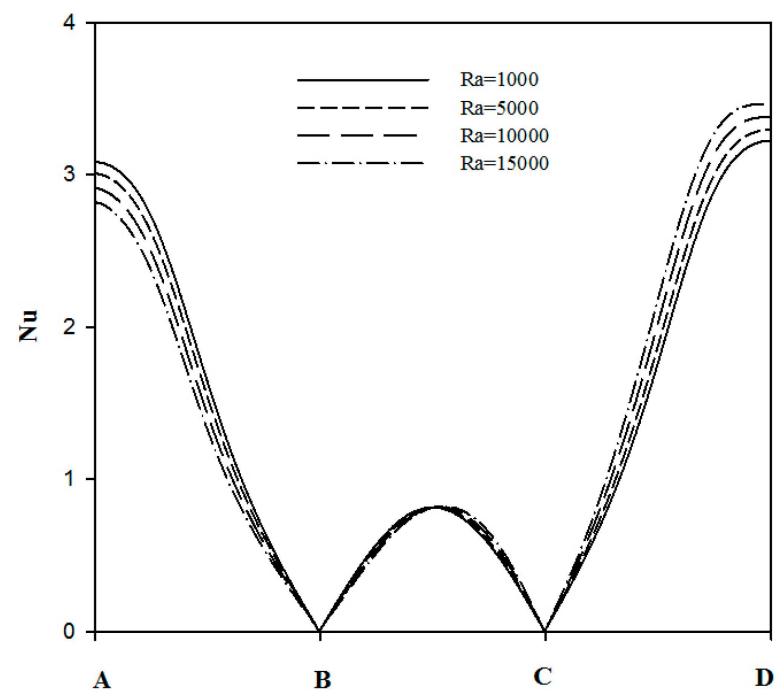

Figure 5. Variation of local Nusselt number for various Rayleigh numbers at $H a=30, A R=0.3$ and $\phi=0.04$.

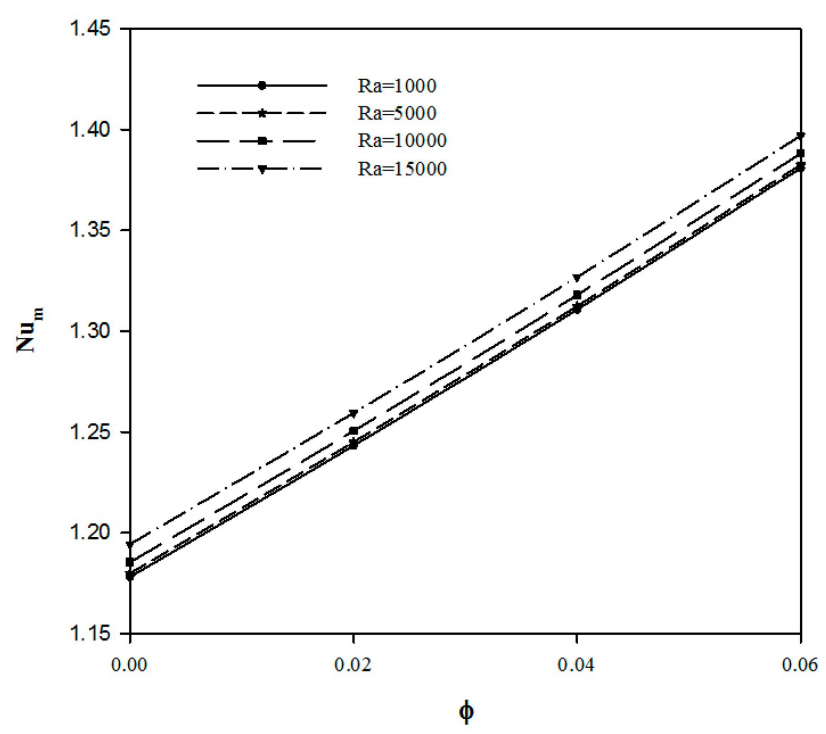

Figure 6. Variation of average Nusselt number for various Rayleigh numbers with $\phi$ for $A R=0.3$ and $H a=30$.

The normalized total entropy generation is illustrated in Figure 7 for the same parameters above. An increase of the nanoparticles volume fraction and Rayleigh number lead to an increase in the 
thermal energy and intensify the nanofluid flow. As a result, a noticeable increase of the total entropy generation with both $\phi$ and $R a$ is recorded in Figure 7. For $R a=1000$, a linear increase of the entropy generation rate is seen. For higher $R a$ values, a faster increasing function is recorded.

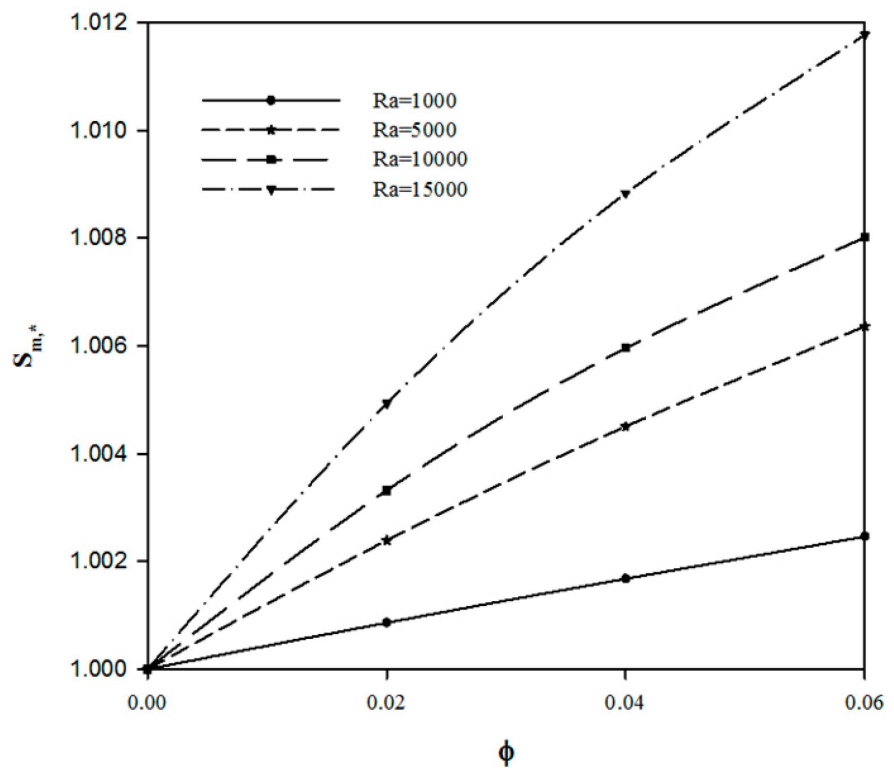

Figure 7. Variation of global entropy generation ratio $\left(S_{m, *}=S_{m} / S_{m, \phi=0}\right)$ for various Rayleigh numbers with $\phi$ for $A R=0.3$ and $H a=30$.

\subsection{Effect of Hartman Number}

The effect of the applied magnetic field is studied by varying Hartman number $(\mathrm{Ha}=0-45)$ at $R a=10,000, \phi=0.04$ and $A R=0.3$. The streamlines patterns, which are presented in Figure 8 , show a continuous reduction in vortex strength with increasing $\mathrm{Ha}$. When $\mathrm{Ha}=0$, the vortex rotates strongly under the effect of natural convection. This limits it to within the main cavity. Increasing $\mathrm{Ha}$ increases the suppression force, which opposes the convection currents and this enables the weakened vortex to penetrate symmetrically through the cavity grooves. A threshold value of $H a=30$ can be characterized at which the penetration effect starts. Before this threshold value, the isotherms manifest a disturbed pattern, which is an indication of the convection dominance. Beyond the threshold value, evenly distributed isotherms are noticed, which indicates a weakening of the convection. In the absence of the magnetic field $(\mathrm{Ha}=0)$, the entropy generation concentrators are not only localized along the vertical hot and cold walls, but the entropy is also generated from a region localized in the middle cavity. However, the later region diminishes with increasing $\mathrm{Ha}$ number. The local Nusselt number shown in Figure 9 indicates a convection effect at $H a=0$, where asymmetric distribution along the hot walls is noticed. The symmetrical behavior is mostly attained with increasing $H a$. It is worth mentioning that the local Nusselt number increases with $\mathrm{Ha}$ along the hot upper wall (AB) only. This might be attributed to the magnetic field effect in carrying the hot nanofluid close to the wall into the cavity. The average Nusselt number normalized by that of pure fluid $\left(\mathrm{Nu}_{\mathrm{m}}, \phi=0\right)$ is presented in Figure 10 . The noticed increase of the normalized Nusselt number with $\mathrm{Ha}$ reflects that the drag action of the magnetic field on the nanofluid is less than that on pure fluid. 

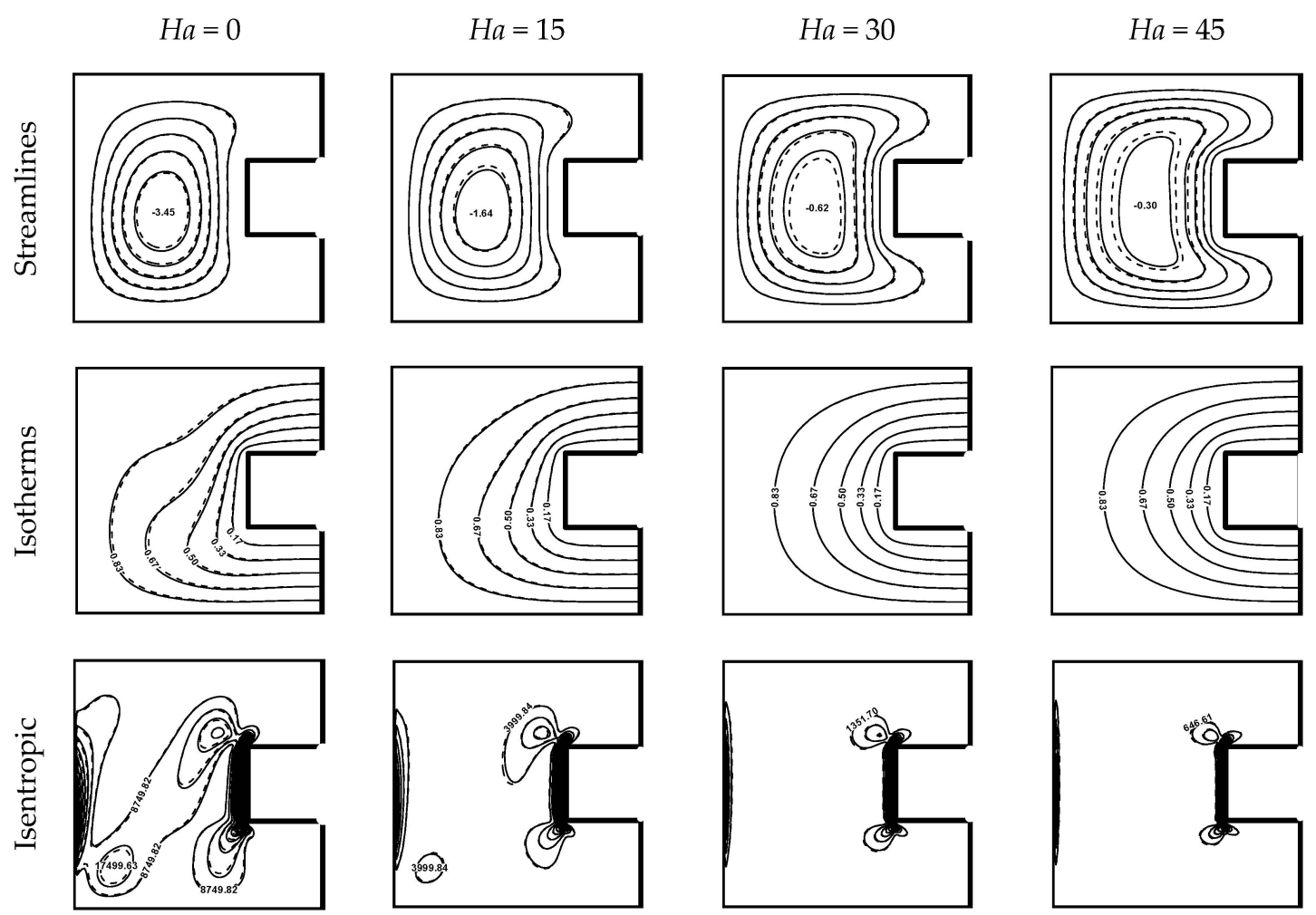

Figure 8. The effects of Hartmann numbers on the Streamlines, Isotherm and Entropy generation for pure-water (-) and nanofluid $\phi=0.04$ (- - ) at $R a=10,000$ and $A R=0.3$.

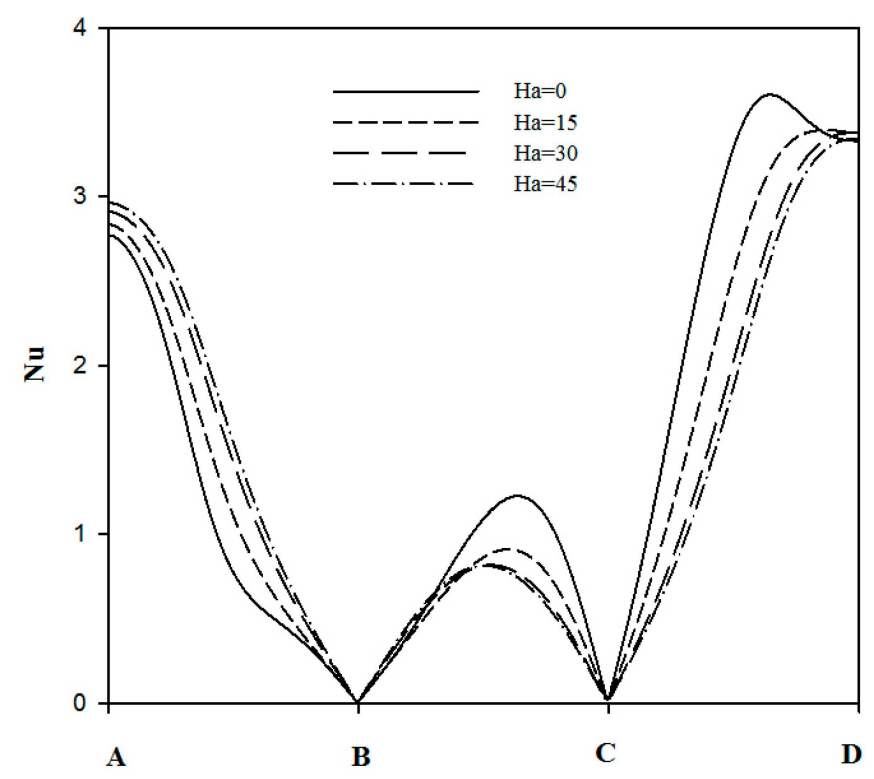

Figure 9. Variation of local Nusselt number for various Hartman numbers at $R a=10,000, A R=0.3$ and $\phi=0.04$. 


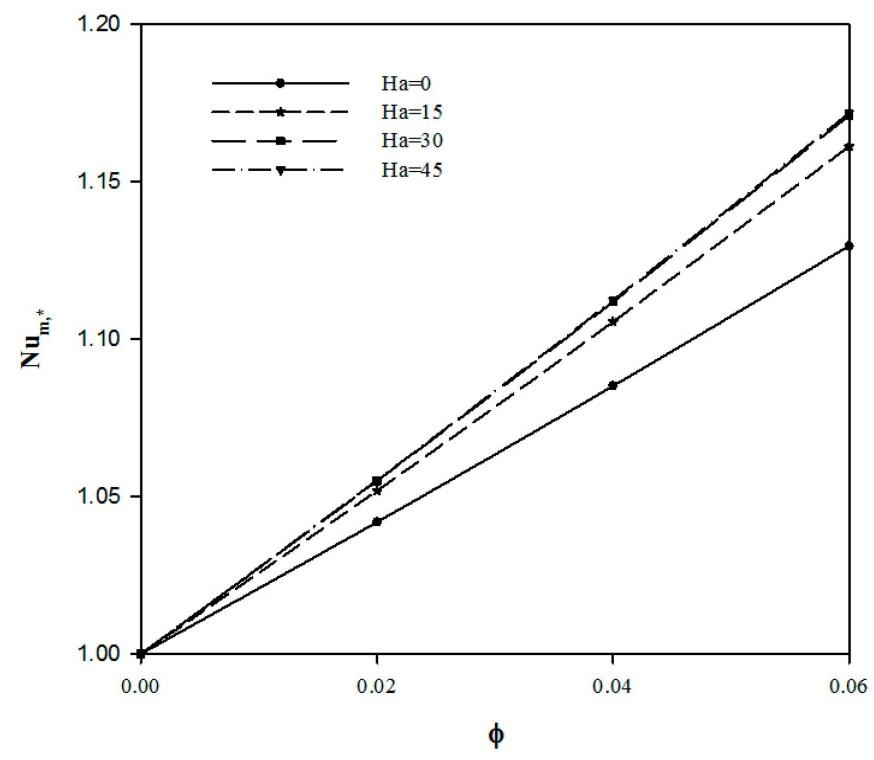

Figure 10. Variation of average Nusselt number ratio $\left(\mathrm{Nu}_{\mathrm{m}, *}=\mathrm{Nu} / \mathrm{Nu}_{\mathrm{m}, \phi=0}\right)$ for various Hartman number with $\phi$ at $R a=10,000$ and $A R=0.3$.

The entropy generation rate with $\mathrm{Ha}$ is shown in Figure 11. Since the natural convection is already weak at $R a=1000$, there is no pronounced action of the magnetic field. However, there is a steep reduction of the entropy generation rate with $\mathrm{Ha}$ within $\mathrm{Ra}>1000$. This steep reduction is up to the threshold Hartman number value. To evaluate the thermal performance of the present geometry with its physical constraints, we adopted the $\varepsilon$ criterion proposed by Ismael et al. [32]. It is the ratio of the total entropy generation to the average Nusselt number. According to this criterion, which is depicted in Figure 12, it seems that applying the magnetic field at low Rayleigh number $(R a=1000)$ is $a$ useless process. Meanwhile, for higher $R a$ values $(R a>1000)$, the magnetic field improves the thermal performance. A value of $\mathrm{Ha}=30 \mathrm{can}$ be accepted as the best if one considers the power consumed in the magnet generating the magnetic field.

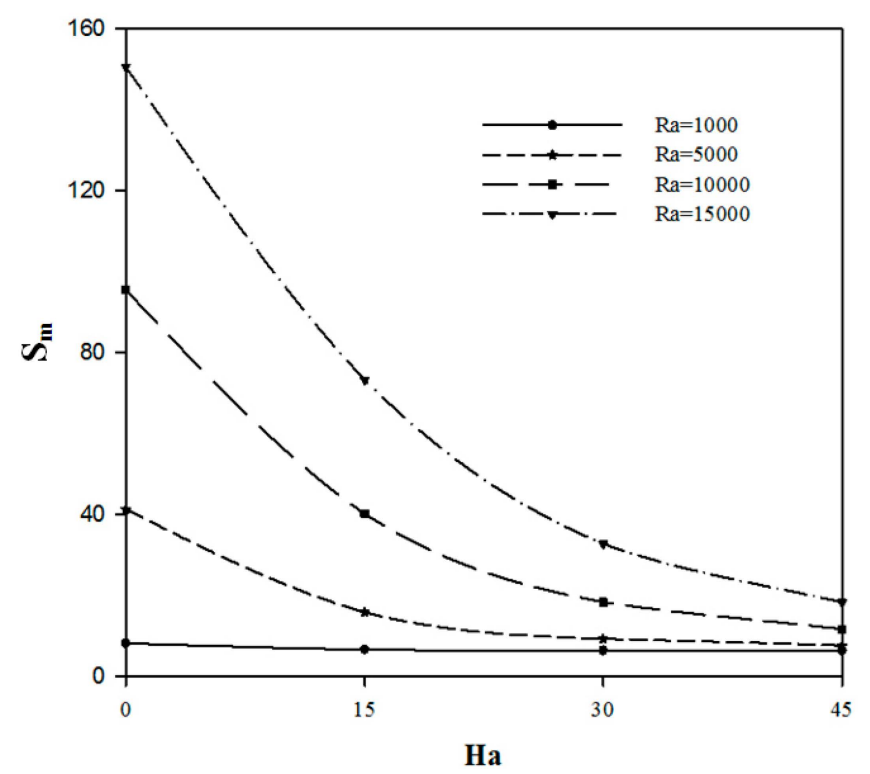

Figure 11. Variation of global entropy generation for various Hartman numbers with $R a$ for $A R=0.3$, and $\phi=0.04$. 


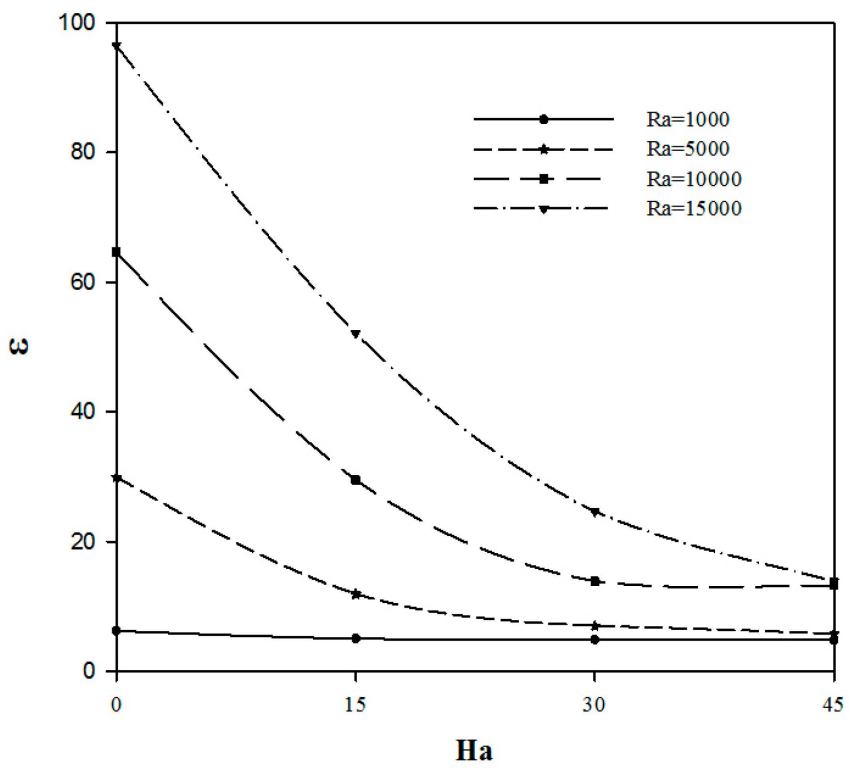

Figure 12. Variation of $\varepsilon\left(\varepsilon=\mathrm{S}_{\mathrm{m}} / \mathrm{Nu}_{\mathrm{m}}\right)$ for various Rayleigh numbers and Hartman numbers for $A R=0.3$ and $\phi=0.04$.

\subsection{Effect of the Aspect Ratio}

Figure 13 shows the contour maps for different aspect ratio at $R a=10,000, \phi=0.0,0.04$ and $H a=30$. For very small aspect ratio $(A R=0.1)$, the available free space in the square-like cavity enables a clockwise vortex with bit concavity close to the cold rib. Increasing the aspect ratio limits the space available for vertex rotation, which leads to a weakened strength of rotation. When $A R$ is further increased to $A R=0.7$, the cavity grooves look like stagnant regions. The lower aspect ratio cavity $(A R=0.1)$ limits the heat outfall, which in turn limits the thermal boundary layer around the rib. The thermal boundary layer is developed when $A R$ increases. A pure conduction is noticed within the cavity grooves. This is because the little vertical distance between the horizontal hot and cold walls. The isentropic lines show that the entropy generation rate is significantly increased with increasing the aspect ratio. However, the dashed contours of $\phi=0.4$ indicate to little effect of nanoparticles on the nanofluid flow, heat transfer, and entropy generation field.
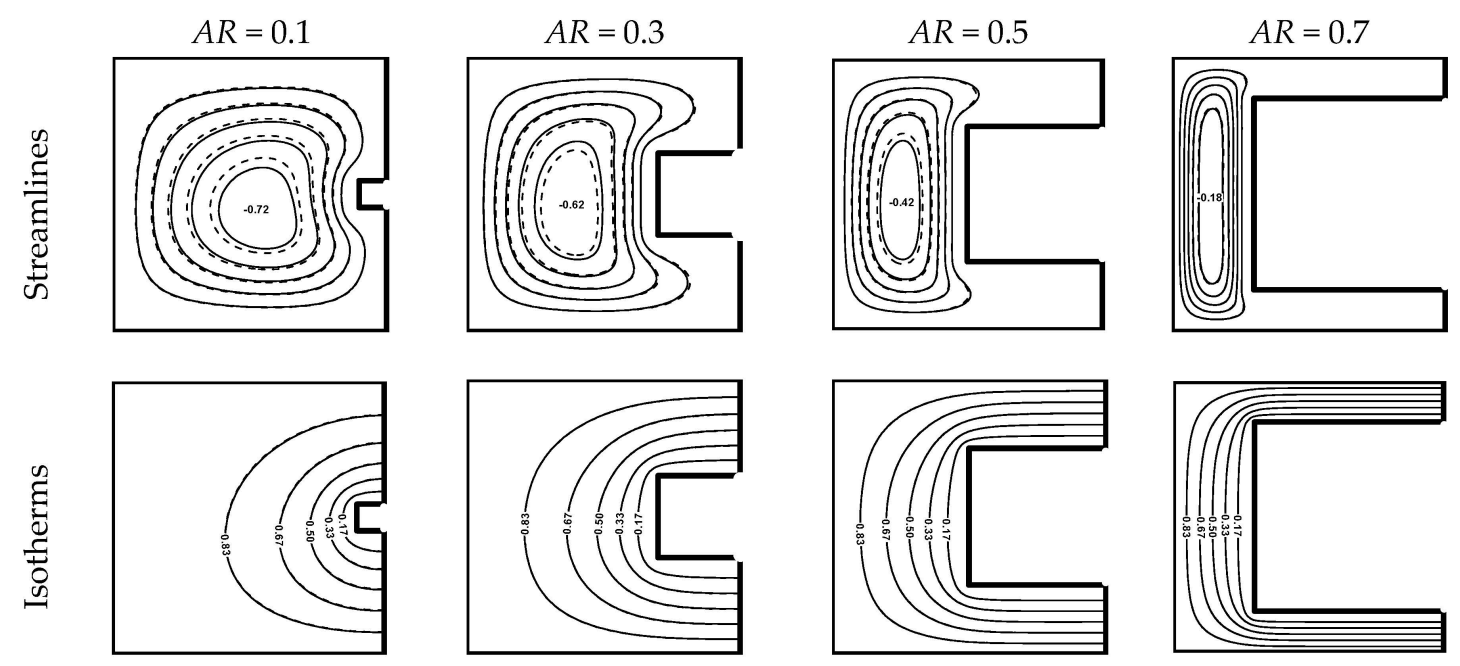

Figure 13. Cont. 

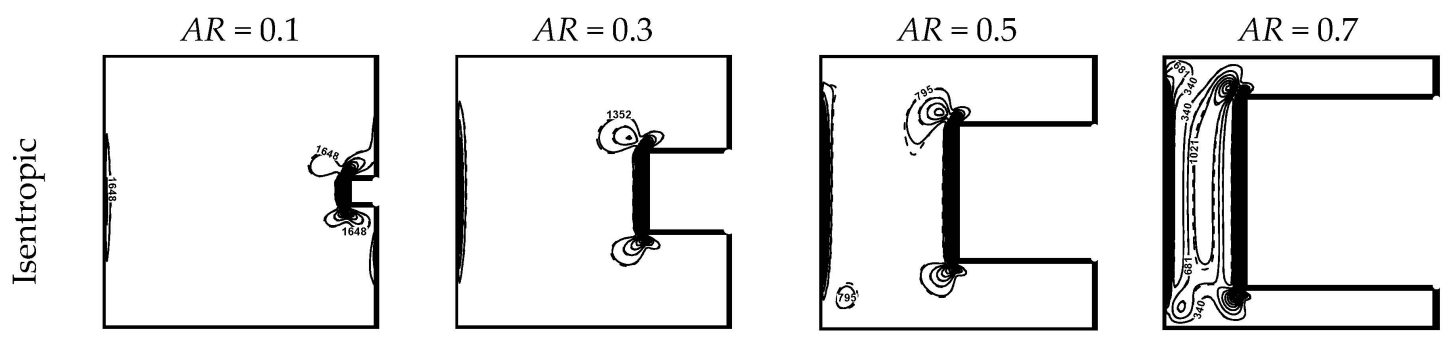

Figure 13. The effects of $A R$ on the Streamlines, Isotherms and Isentropic lines for nanofluid at $\phi=0$, $0.04, R a=10,000$ and $H a=30$.

The local Nusselt number distributions displayed in Figure 14 shows that for low aspect ratio, the hot walls contribute in heat transfer with lesser discrepancy. Increasing the aspect ratio leads to significant contribution weights among the hot walls in heat transfer. Figure 15 clearly shows that the aspect ratio is significantly increased the average Nusselt number. Moreover, enhancement percentages in the average Nusselt number are $19.5 \%$ and $17.6 \%$ for $\phi=0.06$ compared to pure fluid ( $\phi=0.0$ ) when the aspect ratio increased from 0.1 to 0.7 . This result can be attributed to the limited space available, which reduces the strength of vortex rotation and then limits the utilization of nanoparticles addition. The total entropy generation increases with increasing the aspect ratio, as shown in Figure 16. Recalling Figure 15, it can be concluded that the heat transfer irreversibility has a great role in generating the entropy. It is worthwhile to show that the entropy generation rate decreases with aspect ratio $A R=0.1-0.5$ at the same rate, while at $A R=0.7$, the decreasing trend is less steep. The percentage reductions in total entropy generation are $96.27 \%$ and $48.17 \%$ for $\mathrm{Ha}=45$ compared to zero magnetic field when the aspect ratio increased from 0.1 to 0.7 . Eventually, and according to the $\varepsilon$ total entropy/Nusselt number criterion, the applied magnetic field serves in improving the performance (see Figure 17). A threshold value of $H a=30$ may be economically the best value for the applied magnetic field.

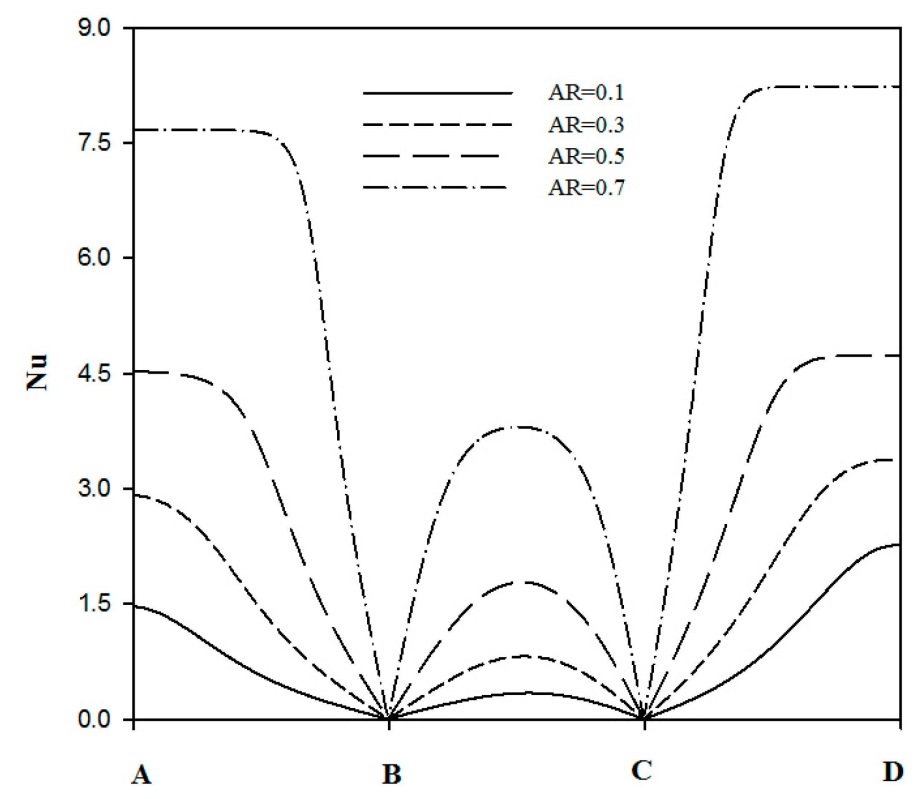

Figure 14. Variation of local Nusselt number for various $A R$ at $\phi=0.04, R a=10,000$ and $H a=30$. 


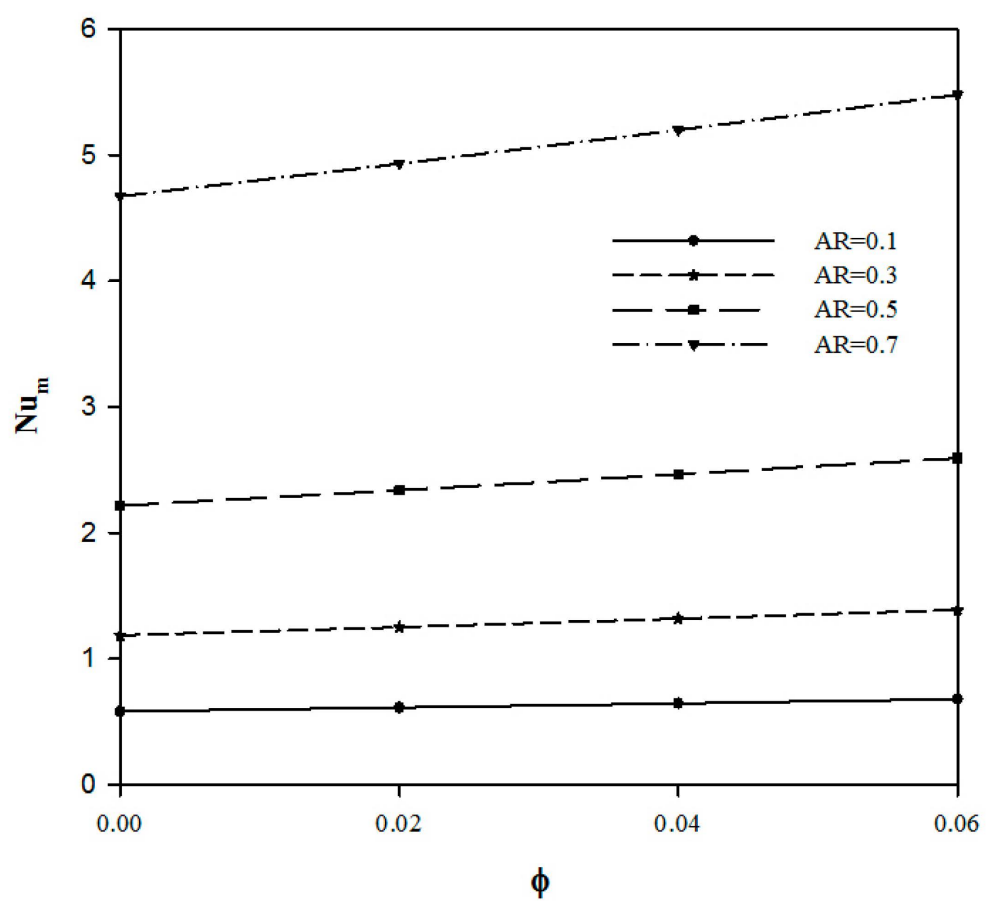

Figure 15. Variation of average Nusselt number for various $A R$ at $R a=10,000$ and $H a=30$.

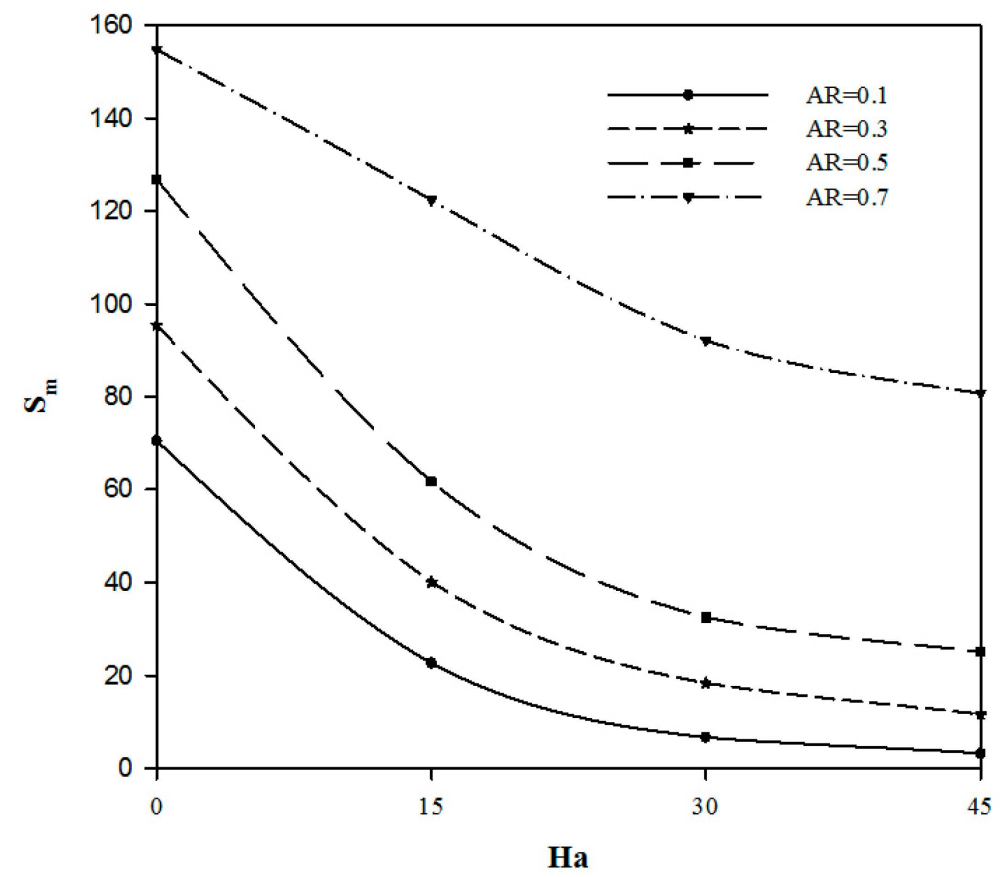

Figure 16. Variation of average Entropy generation for various $A R$ with Hartman numbers for $R a=10,000$ and $\phi=0.04$. 


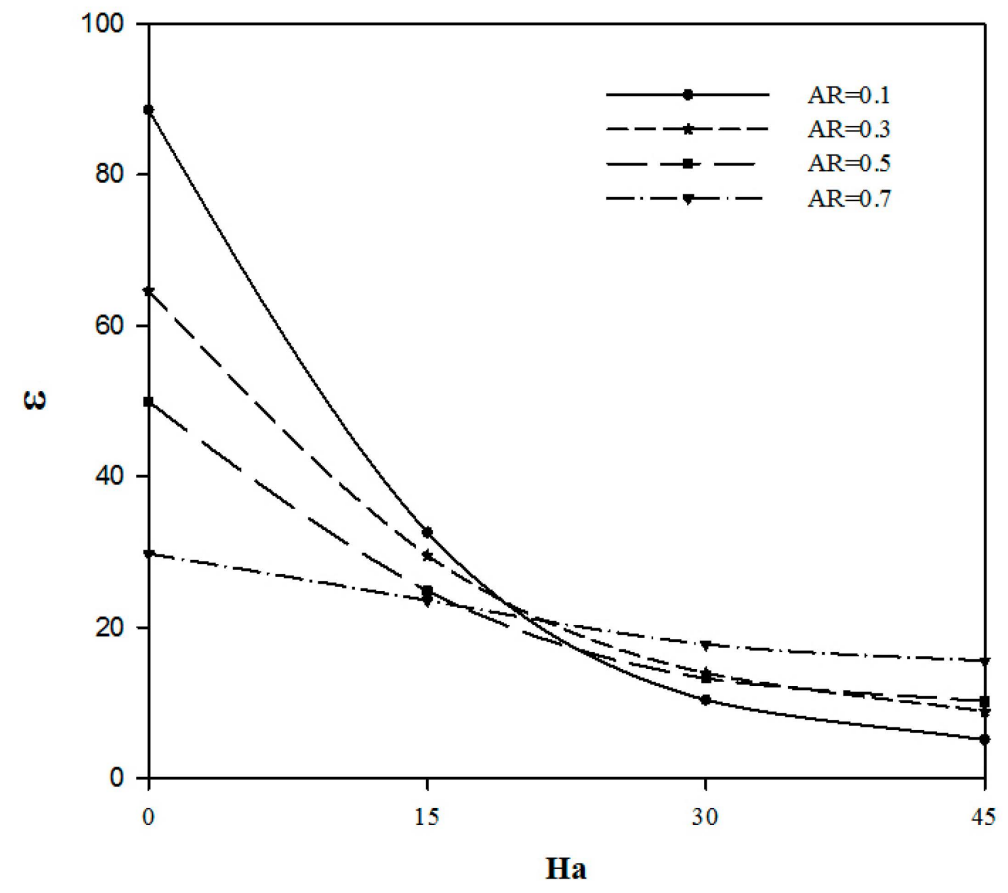

Figure 17. Variation of $\varepsilon\left(\varepsilon=\mathrm{S}_{\mathrm{m}} / \mathrm{Nu}_{\mathrm{m}}\right)$ for various $A R$ with Hartman numbers for $R \mathrm{a}=10,000$ and $\phi=0.04$.

\section{Conclusions}

Entropy generation and natural convection of $\mathrm{CuO}$-water nanofluid in a C-shaped cavity subjected to a horizontal uniform magnetic field is numerically studied. The effects of nanoparticles volume fraction, Rayleigh number, Hartman number, and the aspect ratio are studied. The effect of Brownian motion is considered in the nanofluid properties. The results have led to the following concluding remarks.

(1) The addition of nanoparticles enhances the convective heat transfer inside the C-shaped cavity at all Rayleigh numbers, whereas the entropy generation increases with increasing the volume fraction of the nanoparticles. This increase becomes fast at higher Rayleigh number.

(2) The average Nusselt number increases considerably when the hot and cold walls become narrower, i.e., at higher aspect ratio.

(3) The nanofluid utilization becomes more pronounced at lower aspect ratio.

(4) The applied magnetic field is an inactive process at lower Rayleigh number.

(5) The entropy generation rate decreases rapidly with the applied magnetic field.

(6) A threshold value of Hartman number equal to 30 can give the best thermal performance in the C-shaped cavity.

Acknowledgments: The authors wish to express their sincere thanks to the competent Reviewers for the valuable comments and suggestions.

Author Contributions: Ali Chamkha has directed to achieve this physical problem and proposed the formulation of this problem and has edited the complete manuscript. Abbas Kasaeipoor and Taher Armaghani conducted the numerical solution and post processed the results. Muneer Ismael wrote the sections and analyzed the physical behaviors of some results of this manuscript. All authors contributed in directing the conclusions and assisted in revising the manuscript according to the Reviewers comments. All authors have read and approved the final manuscript.

Conflicts of Interest: The authors declare no conflict of interest. 


\section{Nomenclature}

$\mathrm{B}_{0} \quad$ Magnetic field strength, $T$

$C_{p} \quad$ Specific heat, $J \cdot \mathrm{kg}^{-1} \cdot \mathrm{K}^{-1}$

$g \quad$ Gravitational acceleration, $m \cdot s^{2}$

$H \quad$ Length of heat source, $m$

$\mathrm{Ha}$ Hartmann number, $B_{0} L \sqrt{\sigma_{f} / \rho_{f} v_{f}}$

$k$ Thermal conductivity, $W \cdot m^{-1} \cdot K^{-1}$

$L \quad$ Length of cavity, $m$

$\mathrm{Nu} \quad$ Local Nusselt number

$N u_{\mathrm{m}} \quad$ Average Nusselt number of heat source

$p \quad$ Fluid pressure, $\mathrm{Pa}$

$P \quad$ Dimensionless pressure, $p L / \rho_{n f} \alpha_{f}^{2}$

Pr Prandtl number, $v_{\mathrm{f}} / \alpha_{\mathrm{f}}$

$T$ Temperature, $K$

$T_{c} \quad$ Cold wall temperature, $K$

$T_{h} \quad$ Hot wall temperature, $K$

$u, v \quad$ Velocity components in $x, y$ directions,$m \cdot s^{-1}$

$U, V \quad$ Dimensionless Velocity components,

$(u, v) L / \alpha_{f}$

$x, y \quad$ Cartesian coordinates, $m$

$X, Y \quad$ Dimensionless coordinates, $(x, y) / L$

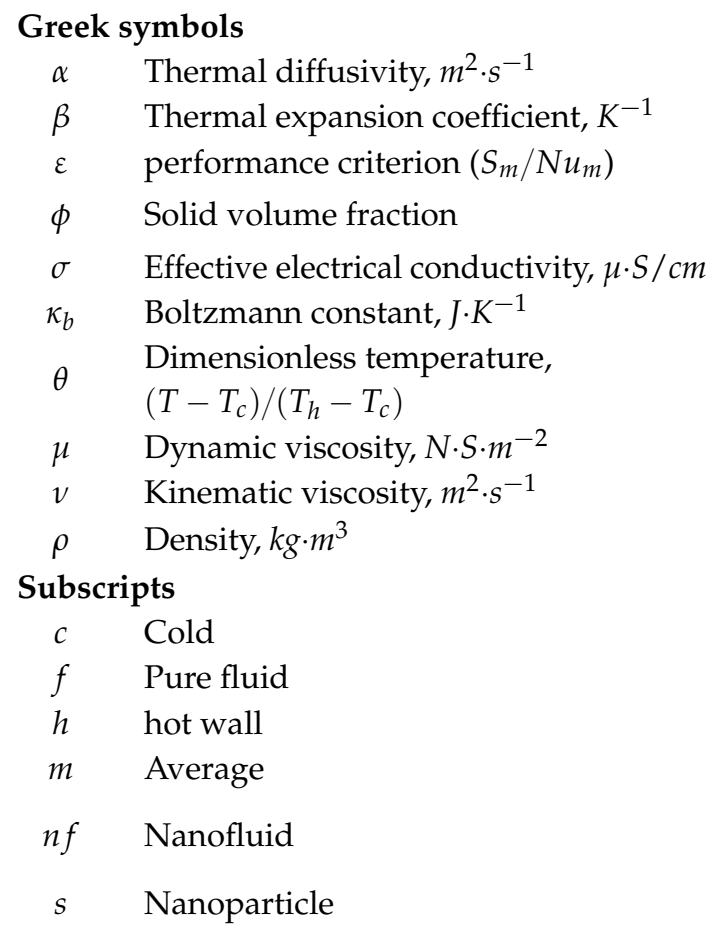

\section{References}

1. Bejan, A. A study of entropy generation in fundamental convective heat transfer. J. Heat Transf. 1979, 101, 718-725. [CrossRef]

2. Bejan, A. Second-law analysis in heat transfer and thermal design. Adv. Heat Transf. 1982, 15, 1-58. [CrossRef]

3. Bejan, A. Entropy Generation Minimization; CRC Press: Boca Raton, FL, USA, 1995.

4. Mahmud, S.; Fraser, R.A. Second law analysis of heat transfer and fluid flow inside a cylindrical annular space. Exergy Int. J. 2002, 2, 322-329. [CrossRef]

5. Mahmud, S.; Islam, A.K.M.S. Laminar free convection and entropy generation inside an inclined wavy enclosure. Int. J. Therm. Sci. 2003, 42, 1003-1012. [CrossRef]

6. Bouabid, M.; Magherbi, M.; Hidouri, N.; Ben Brahim, A. Entropy generation at natural convection in an inclined rectangular cavity. Entropy 2011, 13, 1020-1033. [CrossRef]

7. Cheng, X.; Liang, X. Discussion on the applicability of entropy generation minimization to the analyses and optimizations of thermodynamic processes. Energy Convers. Manag. 2013, 73, 121-127. [CrossRef]

8. Baytas, A.C. Entropy generation for natural convection in an inclined porous cavity. Int. J. Heat Mass Transf. 2000, 43, 2089-2099. [CrossRef]

9. Al-Hadhrami, A.K.; Elliott, L.; Ingham, D.B. A New model for viscous dissipation in porous media across a range of permeability values. Transp. Porous Media 2003, 53, 117-122. [CrossRef]

10. Mahmud, S.; Fraser, R.A. Magneto-hydrodynamic free convection and entropy generation in a square porous cavity. Int. J. Heat Mass Transf. 2004, 47, 3245-3256. [CrossRef]

11. Hooman, K.; Ejlali, A. Entropy generation for forced convection in a porous saturated circular tube with uniform wall temperature. Int. Commun. Heat Mass Transf. 2007, 34, 408-419. [CrossRef]

12. Zahmatkesh, I. On the importance of thermal boundary conditions in heat transfer and entropy generation for natural convection inside a porous enclosure. Int. J. Therm. Sci. 2008, 47, 339-346. [CrossRef]

13. Varol, Y.; Oztop, H.F.; Pop, I. Entropy generation due to natural convection in non-uniformly heated porous isosceles triangular enclosures at different positions. Int. J. Heat Mass Transf. 2009, 52, 1193-1205. [CrossRef]

14. Basak, T.; Kaluri, R.S.; Balakrishnan, A.R. Entropy generation during natural convection in a porous cavity: Effect of thermal boundary conditions. Numer. Heat Transf. 2012, 62, 336-364. [CrossRef] 
15. Choi, S.U.S.; Eastman, J.A. Enhancing Thermal Conductivity of Fluid with Nanoparticles. In Proceedings of 1995 ASME International Mechanical Engineering Congress and Exhibition, San Francisco, CA, USA, 12-17 November 1995.

16. Aminossadati, S.M.; Ghasemi, B. The effects of orientation of an inclined enclosure on laminar natural convection. Int. J. Heat Technol. 2005, 23, 43-49.

17. Ghasemi, B.; Aminossadati, S.M. Brownian motion of nanoparticles in a triangular enclosure with natural convection. Int. J. Therm. Sci. 2010, 49, 931-940. [CrossRef]

18. Abu-Nada, E.; Chamkha, A.J. Effect of nanofluid variable properties on natural convection in enclosures filled with a CuO-EG-water nanofluid. Int. J. Therm. Sci. 2010, 49, 2339-2352. [CrossRef]

19. Nemati, H.; Frhadi, M.; Sedighi, K.; Ashorynejad, H.R.; Fattahi, E. Magnetic field effects on natural convection flow of nanofluid in a rectangular cavity using the Lattice Boltzmann model. Sci. Iran. 2012, 19, 303-310. [CrossRef]

20. Mahmoudi, A.H.; Pop, I.; Shahi, M. Effect of magnetic field on natural convection in a triangular enclosure filled with nanofluid. Int. J. Therm. Sci. 2012, 59, 126-140. [CrossRef]

21. Habibi, M.M.; Pop, I. Natural convection flow and heat transfer in an eccentric annulus filled by Copper nanofluid. Int. J. Heat Mass Transf. 2013, 61, 353-364. [CrossRef]

22. Sheikhzadeh, G.A.; Dastmalchi, M.; Khorasanizadeh, H. Effects of nanoparticles transport mechanisms on $\mathrm{Al}_{2} \mathrm{O}_{3}$-water nanofluid natural convection in a square enclosure. Int. J. Therm. Sci. 2013, 66, 51-62. [CrossRef]

23. Sheikholeslami, M.; Gorji-Bandpy, M.; Seyyedi, S.M.; Ganji, D.D.; Rokni, H.B.; Soleimani, S. Application of LBM in simulation of natural convection in a nanofluid filled square cavity with curve boundaries. Powder Technol. 2013, 247, 87-94. [CrossRef]

24. Sheikholeslami, M.; Gorji-Bandpy, M.; Ellahi, R.; Zeeshan, A. Simulation of MHD CuO-water nanofluid flow and convective heat transfer considering Lorentz forces. J. Magn. Magn. Mater. 2014, 369, 69-80. [CrossRef]

25. Kashani, S.; Ranjbar, A.A.; Mastiani, M.; Mirzaei, H. Entropy generation and natural convection of nanoparticle-water mixture (nanofluid) near water density inversion in an enclosure with various patterns of vertical wavy walls. Appl. Math. Comput. 2014, 226, 180-193. [CrossRef]

26. Cho, C.-C.; Yau, H.-T.; Chiu, C.-H.; Chiu, K.-C. Numerical investigation into natural convection and entropy generation in a nanofluid-filled U-shaped cavity. Entropy 2015, 17, 5980-5994. [CrossRef]

27. Ting, T.W.; Hung, Y.M.; Guo, N. Entropy generation of viscous dissipative nanofluid flow in thermal non-equilibrium porous media embedded in microchannels. Int. J. Heat Mass Transf. 2015, 81, 862-877. [CrossRef]

28. Mahmoudi, A.; Mejri, I.; Abbassi, M.A.; Omri, A. Analysis of the entropy generation in a nanofluid-filled cavity in the presence of magnetic field and uniform heat generation/absorption. J. Mol. Liq. 2014, 198, 63-77. [CrossRef]

29. Aghaei, A.; Khorasanizadeh, H.; Sheikhzadeh, G.; Abbaszadeh, M. Numerical study of magnetic field on mixed convection and entropy generation of nanofluid in a trapezoidal enclosure. J. Magn. Magn. Mater. 2016, 403, 133-145. [CrossRef]

30. Kefayati, G.H.R. Simulation of heat transfer and entropy generation of MHD natural convection of non-Newtonian nanofluid in an enclosure. Int. J. Heat Mass Transf. 2016, 92, 1066-1089. [CrossRef]

31. Ellahi, R.; Hassan, M.; Zeeshan, A. Shape effects of nanosize particles in $\mathrm{Cu}-\mathrm{H}_{2} \mathrm{O}$ nanofluid on entropy generation. Int. J. Heat Mass Transf. 2015, 81, 449-456. [CrossRef]

32. Ismael, M.A.; Armaghani, T.; Chamkha, A.J. Conjugate heat transfer and entropy generation in a cavity filled with a nanofluid-saturated porous media and heated by a triangular solid. J. Taiwan Inst. Chem. Eng. 2015, in press. [CrossRef]

33. Biserni, C.; Rocha, L.A.O.; Stanescu, G.; Lorenzini, E. Constructal H-shaped cavities according to Bejan's theory. Int. J. Heat Mass Transf. 2007, 50, 2132-2138. [CrossRef]

34. Mahmoodi, M. Numerical simulation of free convection of a nanofluid in L-shaped cavities. Int. J. Therm. Sci. 2011, 50, 1731-1740. [CrossRef]

35. Mahmoodi, M.; Hashemi, S.M. Numerical study of natural convection of a nanofluid in C-shaped enclosures. Int. J. Therm. Sci. 2012, 55, 76-89. [CrossRef]

36. Cho, C.-C.; Yau, H.-T.; Chen, C.-K. Enhancement of natural convection heat transfer in a U-shaped cavity filled with $\mathrm{Al}_{2} \mathrm{O}_{3}$-water nanofluid. Therm. Sci. 2012, 16, 1317-1323. [CrossRef] 
37. Mansour, M.A.; Bakeir, M.A.; Chamkha, A. Natural convection inside a C-shaped nanofluid-filled enclosure with localized heat sources. Int. J. Numer. Method Heat Fluid Flow 2014, 24, 1954-1978. [CrossRef]

38. Mojumder, S.; Saha, S.; Saha, S.; Mamun, M.A.H. Effect of magnetic field on natural convection in a C-shaped cavity filled with ferrofluid. Procedia Eng. 2015, 105, 96-104. [CrossRef]

39. Kasaeipoor, A.; Ghasemi, B.; Aminossadati, S.M. Convection of Cu-water nanofluid in a vented T-shaped cavity in the presence of magnetic field. Int. J. Therm. Sci. 2015, 94, 50-60. [CrossRef]

40. Al-Zamily, A.M.J. Effect of magnetic field on natural convection in a nanofluid-filled semi-circular enclosure with heat flux source. Comput. Fluids 2014, 103, 71-85. [CrossRef]

41. Sheikholeslami, M.; Ganji, D.D.; Gorji-Bandpy, M.; Soleimani, S. Magnetic field effect on nanofluid flow and heat transfer using KKL model. J. Taiwan Inst. Chem. Eng. 2014, 45, 795-807. [CrossRef]

42. Öğüt, E.B. Natural convection of water-based nanofluids in an inclined enclosure with a heat source. Int. J. Therm. Sci. 2009, 48, 2063-2073. [CrossRef]

43. Masoumi, N.; Sohrabi, N.; Behzadmehr, A. A new model for calculating the effective viscosity of nanofluids. J. Phys. D 2009, 42, 055501. [CrossRef]

44. Chon, C.H.; Kihm, K.D.; Lee, S.P.; Choi, S.U.S. Empirical correlation finding the role of temperature and particle size for nanofluid $\left(\mathrm{Al}_{2} \mathrm{O}_{3}\right)$ thermal conductivity enhancement. Appl. Phys. Lett. 2005, 87, 153107. [CrossRef]

45. Mintsa, H.A.; Roy, G.; Nguyen, C.T.; Doucet, D. New temperature dependent thermal conductivity data for water-based nanofluids. Int. J. Therm. Sci. 2009, 48, 363-371. [CrossRef]

46. Popa, C.V.; Kasaeian, A.B.; Nasiri, S.; Korichi, A.; Polidori, G. Natural convection heat and mass transfer modeling for $\mathrm{Cu} /$ water and $\mathrm{CuO} /$ water nanofluids. Adv. Mech. Eng. 2013. [CrossRef]

47. Maxwell, J.C. A Treatise on Electricity and Magnetism, 2nd ed.; Oxford University Press: Cambridge, UK, 1904.

48. Patankar, S. Numerical Heat Transfer and Fluid Flow; CRC Press: Boca Raton, FL, USA, 1980.

49. Pirmohammadi, M.; Ghassemi, M. Effect of magnetic field on convection heat transfer inside a tilted square enclosure. Int. Commun. Heat Mass Transf. 2009, 36, 776-780. [CrossRef]

(C) 2016 by the authors; licensee MDPI, Basel, Switzerland. This article is an open access article distributed under the terms and conditions of the Creative Commons by Attribution (CC-BY) license (http://creativecommons.org/licenses/by/4.0/). 